
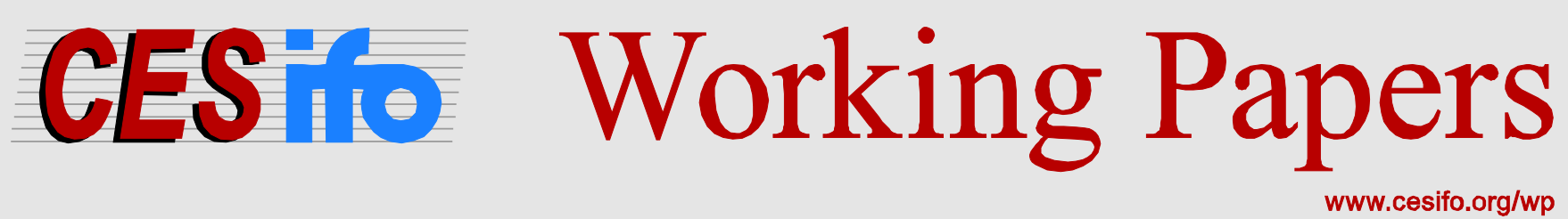

\title{
Carbon Emissions Scenarios in Europe Based on an Endogenous Growth Model
}

\author{
Anna Ciesielski \\ Richard S.J. Tol
}

CESIFO WORKING PAPER NO. 4971

CATEGORY 10: ENERGY AND CliMATE ECONOMICS

SEPTEMBER 2014

An electronic version of the paper may be downloaded

- from the SSRN website:

- from the RePEc website:

- from the CESifo website:

www.SSRN.com

Www.RePEc.org

www.CESifo-group.org/wp 


\title{
Carbon Emissions Scenarios in Europe Based on an Endogenous Growth Model
}

\begin{abstract}
Carbon dioxide emissions are a major force driving climate change. We construct scenarios of CO2 emissions from fossil energy until 2100 in Europe. Major innovations are first that economic growth is based on an endogenous economic growth model and second that we calibrate our model to historical data on population and GDP since 1850. We provide statistically valid confidence intervals of economic growth to indicate the accuracy of our forecasts and we show that aggregate forecasts vary with their spatial resolution. We find stronger income divergence between Western- and Eastern European countries than is projected in the 'Middle of the Road' scenario of the so-called Shared Socioeconomic Pathways (SSP2), a framework which was adopted together with the Fifth Assessment Report of the Intergovernmental Panel on Climate Change (IPCC AR5).
\end{abstract}

JEL-Code: Q540.

Keywords: CO2 emissions, endogenous growth, scenarios.

Anna Ciesielski

Ifo Institute - Leibniz Institute for

Economic Research

at the University of Munich

Poschingerstrasse 5

Germany-81679 Munich

ciesielski@ifo.de

\author{
Richard S.J. Tol \\ Department of Economics \\ University of Sussex \\ Jubilee Building Jub-281 \\ UK - BN1 9SL Falmer, Brighton \\ R.Tol@sussex.ac.uk
}

August 29, 2014 


\section{Introduction}

Emission scenarios help to anticipate potential temperature increases and consequential damages. The IPCC Special Report on Emission Scenarios by Nakicenovic et al. (2000) reveals a wide range of projections from near zero emissions worldwide in 2100 to an over tenfold increase compared to 1990. In these scenarios income per capita growth is a major determinant of future emissions, and a great source of uncertainty. Nevertheless, in the scenario literature and in Integrated Assessment Modeling economic growth is not systematically studied, and the underlying growth models do not reflect the rapid development of economic theory since 1990 .

The aim of this study is to construct carbon dioxide emission scenarios for Europe until 2100. We introduce three innovations. First, economic growth is modeled using a recently developed model of endogenous growth by Jones (1995), rather than older models of Solow (1956) or Koopmans (1965). Second, the model is formally calibrated, using data that span a period (1850-2008) longer than the projection period (2008-2100). Third, deriving from the quality of the calibration, this work provides statistically valid confidence intervals of economic growth, which translate into a measure of uncertainty regarding future carbon emissions. Forecasts are made on the country level and for Europe as a whole, so that we can assess the effect of spatial resolution on best projections and confidence intervals. In addition, we compare our results to earlier projections.

In the theoretical literature of environmental economics endogenous growth models have been applied in varied forms. Bovenberg and Smulders (1995) for instance evaluate the impacts of environmental policies on the long run equilibrium in a two sector economy with constant returns to the non-diminishing factor and endogenous pollution-augmenting technological progress. Smulders (1995) investigates the feasibility of long-run economic growth given the scarcity of natural resources and stresses the importance of new growth theory when addressing the limited nature of certain natural resources.

In the Integrated Assessment literature there have been sustained efforts to endogenize technological change. The best known models in this regard are the WITCH model (see Bosetti, Massetti and Tavoni (2007)), the ENTICE model (see Popp (2004)) and the DEMETER model (see Gerlagh and van der Zwaan (2003) and Gerlagh et al. (2004)). These models have in common, that they entail at least two competing energy technologies and endogenized technological change (for further reference on directed technical change 
see also Acemoglu et al. (2012) and Pottier, Hourcade and Espagne (2014)). The WITCH and the DEMETER model are both based on a learning-by-doing approach. However, in these models long-run economic growth is still driven by exogenously given growth rates. To our best knowledge the only calibrated model in which the economic growth engine is specified in the spirit of new growth theory is a CGE model by Bretschger, Ramer and Schwark (2011). The model is calibrated to match a number of different emission trajectories using a Swiss input-output table. As an application the authors simulate the economic effects of potential carbon policies.

In this paper economic growth is modeled based on the product variety approach as first suggested by Romer (1990). We find that in order to keep future carbon emissions until 2100 constant, Western Europe would have to reduce its' energy and emission intensities by roughly $1 \%$ annually, while in Eastern Europe and former USSR countries $0.5 \%$ of annual reductions would be sufficient. This is the case, since our calibrations yield higher annual growth rates in Western Europe than in Eastern Europe and former USSR countries. This is even more striking considering that current per capita carbon emissions in Western Europe are approximately 21\% higher than in Eastern Europe. Because of past economic turmoil our confidence intervals of future carbon emissions turn out to be larger in Eastern Europe and former USSR countries than in Western Europe. In addition, there are relatively large discrepancies between forecasts on the aggregate and on the country level, which in some cases tend to underestimate future growth and thus carbon emissions. In the following section we present and discuss our choice of data sets employed in the calibration. Section 3 proceeds with the methodological approach and our choice of parameter values. A summary of all results will be discussed in section 4 . This entails carbon emissions projections and their corresponding confidence intervals on the country level as well as for Europe as a whole. In addition we provide a comparison of the sum of all country-wise forecasts and the aggregate forecast for Europe. In section 5 we compare our income and emission pathways to the SSP and RCP scenario framework which was codeveloped with the Fifth Asessment Report of the Intergovernmental Panel on Climate Change and in section 6 we conduct a sensitivity analysis regarding the discount rate and the capital share. Finally, section 7 concludes. 


\section{Data}

The data set comprises 23 countries or regions in Europe. In addition, we construct aggregates for Western Europe, Eastern Europe and Europe as a whole. The data set covers annual observations from 1850 to 2008. This allows us to pick up historical time trends and to project those into the further future. Several boundary changes in Europe's past turn the collection of data into a cumbersome business. Because we are interested in time series which are not influenced by the changing geographical size of a country, the data was compiled as if today's borders had been in place since 1850. Former Czechoslovakia, the USSR and Yugoslavia were each aggregated into one region.

\section{Population}

Historical data on population by country is available in Angus Maddison's historical statistics (see Maddison (2010)). Coverage is complete by country and year starting in 1920 . In addition, data are complete in 1850 . This allows for cubic and in rare cases linear interpolation to fill in gaps. In those cases where boundary changes led to a sudden change in the population size we construct a replacement which reflects the current geographical size of the regarding country. Annual population forecasts by country from 2011 to 2100 are provided by the United Nations (see United Nations (2010)). Figure 1 illustrates past and future population growth in Europe and Russia. Apparently, a population maximum is expected to be reached shortly after 2000 .

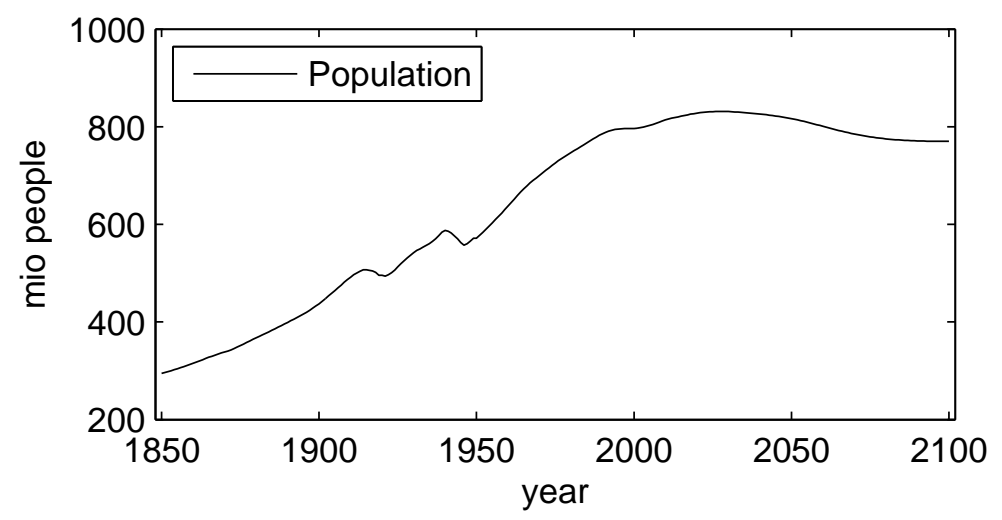

Figure 1: Sample population in total Europe and Russia 


\section{Income}

Income between 1850 and 2008 was taken from Angus Maddison's historical statistics and adjusted to the current geographical size of each country. For some countries there are no observations before 1870 available. In those cases missing observations were filled in by linear data extrapolation. Since 1850 our sample income in Europe and Russia has increased by a factor of 34 (see figure 3). Growth has been relatively constant except for some kinks during the Second World War and the collapse of the German Wall and the communist system.

\section{Capital share}

Past and future capital shares in Europe are controversially discussed. The Kaldor facts (Kaldor (1961)) state that long run capital shares have been relatively constant over time. For a discussion see for instance Kongsamut, Rebelo and Xie (2001), Foellmi and Zweimüller (2008) and Acemoglu (2009). So far the literature has made ample use of their straighforwardness. However, recent empirical findings suggest that in a number of developed countries capital shares have been strongly increasing for some decades. In Blanchard (1997) the estimated capital share in some European countries increases from 0.32 in 1980 to roughly 0.4 in 1995 . Jones (2003) provides empirical data on capital shares in OECD countries since 1960, which have been non-constant over time and in a number of countries in Europe these have been increasing significantly. In this study we assume that the capital share in Europe before 1850 was constant at 25\%; in other words, before 1850 the capital-income ratio assumes its steady-state value. After 2100 we assume the capital share to stagnate at $45 \%$. This premise together with the assumption of a constant population growth rate after 2100 leads to steady-state growth some years later. In between we explore the possibility of an increasing capital share. To keep our results comparable between countries, we assume the same evolution of capital shares in all countries as is given in equation (1), where $(1-\sigma)$ represents the capital share (see also figure 2 ).

$$
1-\sigma=\arctan ((\text { year }-1975) * 0.02) * 0.084+0.35
$$

In section 6 we present a continuum of assumptions regarding the capital share and show that our results are relatively sensitive towards these assumptions. In the bigger part of the literature however, a careful examination of the assumptions regarding the capital share is excluded from the analysis and capital shares are at a constant and at a seemingly 


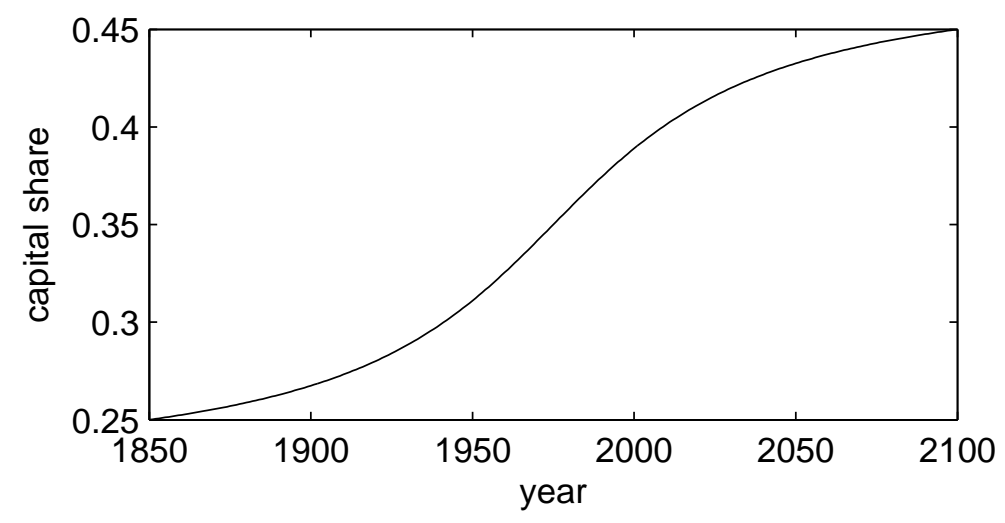

Figure 2: Assumed capital share

arbitrary level.

\section{Energy use and carbon emissions}

Annual data on energy use by country since 1960 is available at the World Bank online data base. Data on annual carbon emissions from fossil fuel by country since 1751 is available in a very comprehensive collection by Boden, Andres and Marland (2013).

Figure 3 illustrates how past carbon emissions in Europe and Russia have been increasing until 1980. Later on we observe their sudden decline, while income continues to grow. Therefore, we assume that future energy and emission intensities until 2100 will continue to decrease. The rate at which both are assumed to decrease will be part of the analysis in section 4 .

\section{Model}

Carbon emissions $\left(X_{t}\right)$ are subdivided into four partially observed components: population $\left(P_{t}\right)$ growth, income per capita $\left(Y_{t} / P_{t}\right)$ growth, changes in the energy intensity $\left(E_{t} / Y_{t}\right)$ and in the emissions intensity $\left(X_{t} / E_{t}\right)$. That is, we use the Kaya identity to decompose carbon emissions ${ }^{1}$ :

$$
X_{t}=P_{t} * \frac{Y_{t}}{P_{t}} * \frac{E_{t}}{Y_{t}} * \frac{X_{t}}{E_{t}}
$$

Our focus is on endogenizing economic growth and on a quantification of the uncertainty that is tied to economic growth. Future population sizes are taken from UN forecasts and

\footnotetext{
${ }^{1}$ As has for instance been done in Hoffert et al. (1998) and Tol and Pacala (2009).
} 

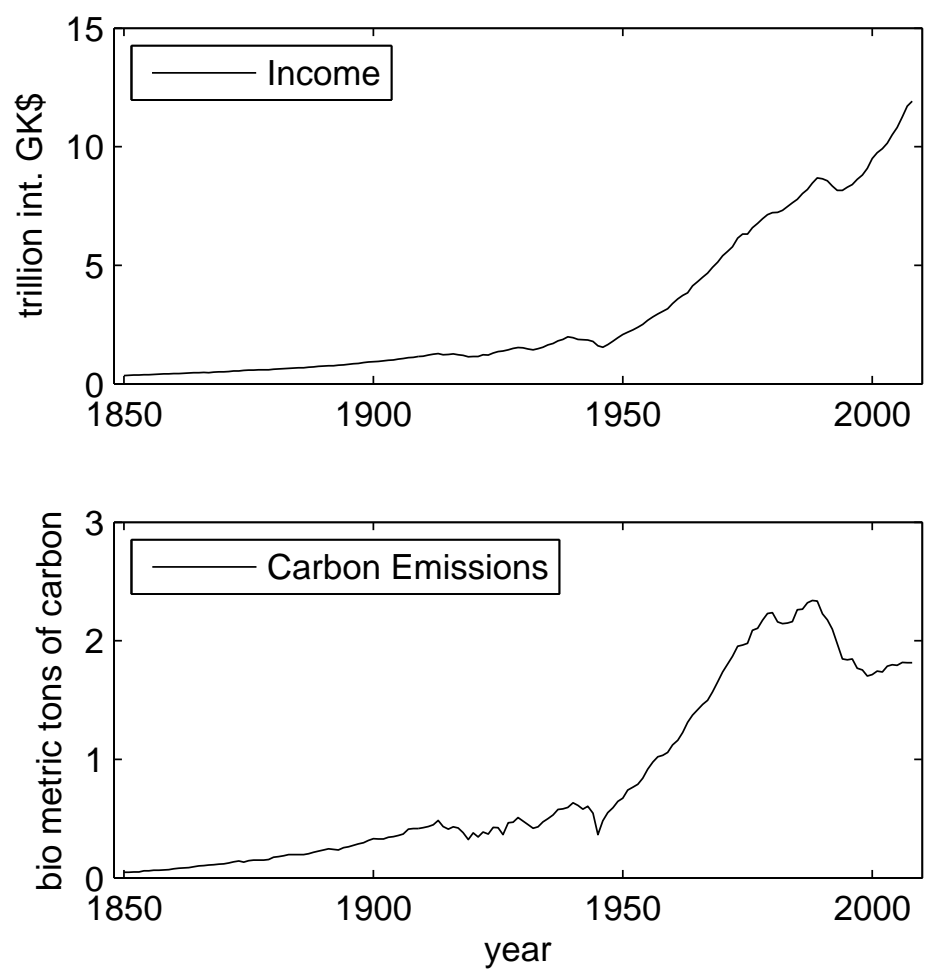

Figure 3: Sample income and carbon emissions in total Europe and Russia

energy and emission intensities are assumed to decrease at constant rates, which will be part of the analysis in section 4 , thus they are outside of our growth model.

The economic model depends on innovation-based growth as described in Romer (1990). Growth is driven endogenously by profit maximizing agents who invest in the creation of new technologies and thereby increase overall productivity. Technological change is characterized as an increasing variety in intermediate products. To circumvent scale effects, which arise for non-zero rates of population growth, we calibrate the model variant of Jones (1995). The aim of this section is to give a brief introduction to the model. For further detail the reader is referred to the original paper.

The economy consists of three sectors, a final output sector, a sector producing intermediate product varieties and a research sector. The latter develops blueprints, needed for the production of additional variants of intermediate goods, which are employed in the production of final output. Economic growth is endogenous in the sense that growth derives from the invention and pursuit of new technologies by profit maximizing agents. 
Final output is derived from labor and a variety of intermediate inputs ${ }^{2}$ :

$$
Y=(\phi L)^{\sigma} \int_{0}^{A} x_{i}{ }^{1-\sigma} d i
$$

where $0<\phi<1$ represents the share of labor, $L$, which is allocated to the production of final output $Y$ and $A$ is a stock of intangible knowledge about the production of variants. It denotes the number of blueprints that is available for the production of intermediate products and thus represents technological progress in the economy. $x_{i}$ denotes the amount of variant $i$ that is employed in the production of final output and $\sigma$ represents the production elasticity. Because symmetric, profit maximizing, monopolistic firms determine the quantities in which intermediate product variants are produced, they are produced in equal amounts using one unit of capital, $K$, for the production of one unit of intermediate input $x: K=A x$. Thus, the social production function above can be reduced to:

$$
Y=(A \phi L)^{\sigma} K^{1-\sigma}
$$

In the research sector the creation of new blueprints profits from the stock of intangible knowledge accumulated in the past and from the labor share $(1-\phi) L$ allocated to the research sector:

$$
\frac{d A}{d t}=\dot{A}=\alpha_{J} A^{\eta_{A}}[(1-\phi) L]^{\eta_{L}}
$$

$\eta_{A}$ and $\eta_{L}$ denote the production elasticities and $\alpha_{J}$ is an exogenous technological parameter.

Each firm in the intermediate sector, having purchased one blueprint from the research sector, acts as a profit maximizing monopolist for the production of its own variant. Since final good production is constant scale, we can consider it as one price-taking firm. Thus intermediate firms maximize their profits by choosing the optimal price of an intermediate input. Production costs in the intermediate sector derive from the cost of capital. Because all firms in the intermediate sector are symmetric, all variants are produced in the same quantity and all firms yield the same profits $\pi$ :

$$
\pi=\sigma(1-\sigma) \frac{Y}{A}
$$

\footnotetext{
${ }^{2}$ From here on we drop the time index.
} 
$r$ represents the interest rate towards capital and is a formal result derived from the profit maximization in the intermediate sector:

$$
r=(1-\sigma)^{2} \frac{Y}{K}
$$

The patent price $P_{A}$ of a blueprint will be bid up among firms in the intermediate sector until it equals the present value of all profits that a monopolist can extract:

$$
P_{A}(t)=\int_{t}^{\infty} e^{-\int_{t}^{\tau} r(s) d s} \pi(\tau) d \tau
$$

In the research sector all earnings derived from the sale of new blueprints to the intermediate sector are allocated to the reimbursement of labor:

$$
w_{L}=P_{A} \frac{\dot{A}}{(1-\phi) L}
$$

where $w_{L}$ denotes wages in the research sector. Hence, there are no profits in the research sector. In the final output sector the marginal cost of labor equals its marginal revenue:

$$
w_{Y}=\sigma \frac{Y}{\phi L}
$$

where $w_{Y}$ denotes wages in the final output sector. In equilibrium both wages are equal.

Households maximize their discounted utility and have constant elasticity preferences:

$$
\begin{gathered}
\max \int_{0}^{\infty} U(c) e^{-\rho t} d t \\
U(c)=\frac{c^{1-\theta}-1}{1-\theta}
\end{gathered}
$$

Lower case $c$ represents per capita consumption. $\theta$ is the elasticity of marginal utility and $\rho$ the discount factor.

Household optimization is subject to the budget constraint:

$$
\dot{K}=r K+w L-P_{A} \dot{A}+A \pi-C-\delta K
$$

where $w$ denotes the equilibrium wage in the research and the final output sector and $\delta$ represents a constant rate of capital depreciation.

On the balanced growth path the economy grows at rate: 


$$
\frac{\dot{A}}{A}=g_{A}=\frac{\eta_{L}}{1-\eta_{A}} n
$$

which derives from equation (5) and

$$
g_{A}=g_{y}=g_{c}
$$

where lower case variables represent per worker ratios. The growth rate of the economy does not depend on its size as in Romer (1990) but on the population growth rate. For a discussion about stylized facts and non-scale models of economic growth see Jones (1995) and Eicher and Turnovsky (1999).

The model is fully determined by a system of four differential equations describing the evolution of the stock of intangible knowledge $A$, the accumulated capital stock $K$, household consumption $C$ and the patent price for new blueprints $P_{A}$ and one static condition regarding wage equality:

$$
\begin{gathered}
\dot{A}=\alpha_{J} A^{\eta_{A}}[(1-\phi) L]^{\eta_{L}} \\
\dot{K}=Y-C-\delta K \\
\dot{C}=\frac{C}{\theta}(r-\rho-\delta-n)+n C \\
\dot{P_{A}}=r P_{A}-\pi \\
\sigma \frac{Y}{\phi L}=P_{A} \alpha_{J} A^{\eta_{A}}[(1-\phi) L]^{\left(\eta_{L}-1\right)}
\end{gathered}
$$

Equation (17) is equvalent to equation (13). Equation (18) representents the optimal path of household consumption maximizing household utility (see equation (11)). Equation (19) is the derivative of equation (8) with regard to time and equation (20) is a static condition of wage equality in the research and the final output sector (see equations (10) and (9)). In order to solve this system of simultaneous differential equations, $A, K, C$ and $P_{A}$ have to be transformed into stationary variables whose equilibrium growth rates are 
zero (for the transformation see the appendix). Numerically we use the relaxation algorithm (see Trimborn (2008)) to solve equations (16) through (20) simultaneously.

We calibrate the model such that the squared residual between observed and calibrated income is minimized. All parameter values are given in table (1). Since the population growth rate, $n$, is non-constant, the numerical solution of the model has to account for transitory dynamics. The resulting pathway of income per capita until 2100 is not on the balanced growth path. We choose our parameters of calibration to be $\eta_{A}$ and $\eta_{L}$, which determine the growth rate of the economy (see equation (14)). Hence, we do not impose any assumption about economic growth on the calibration in the first place, except for the common non-negativity and non-increasing-returns-to-scale constraints. Imposing $\eta_{A}<1$ eliminates unwanted scale effects as in Romer (1990). Economic growth depends on the growth rate of the labor force, rather than on its level.

Table 1: Parameters of the model

\begin{tabular}{llll}
\hline Symbol & Description & Value & Source \\
\hline \hline$\rho$ & discount factor & 0.015 & DICE 2013 \\
$\theta$ & elasticity of marginal utility & 1.45 & DICE model 2013 \\
$(1-\sigma)$ & capital share in final output production & non-const. & see section (2) \\
$\delta$ & capital depreciation rate & 0.1 & DICE model 2013 \\
$n$ & population growth rate & non-const. & own calculations \\
$\alpha_{J}$ & technological shift factor & 1 & assumption \\
$0 \leq \eta_{A} \leq 1$ & productive elasticity of technology & - & parm. of calibration \\
$0 \leq \eta_{L} \leq 1$ & productive elasticity of labor & - & parm. of calibration \\
\hline
\end{tabular}

We construct confidence intervals of future income per capita based on the assumption that $\eta_{A}$ and $\eta_{L}$ follow a truncated multivariate normal distribution. We draw a large sample of random values for $\eta_{A}$ and $\eta_{L}$ and use these to derive their corresponding income per capita projection. The $95 \%$ confidence interval represents all forecasts except for the $2.5 \%$ highest and lowest income per capita projections.

To determine the distribution of $\eta_{A}$ and $\eta_{L}$, we derive their covariance matrix as in Amemiya (1985). Assuming that the residuals, $\epsilon_{i}$, between our observed and estimated income from 2009 to 2100 are independently and identically normally distributed, which 
is a bold assumption since we are dealing with time series, our income estimates, $y_{i}$, follow the distribution below:

$$
y_{i} \sim N\left(\mu_{i}, \sigma^{2} I\right)=\frac{1}{\sqrt{2 \pi \sigma^{2}}} e^{-\frac{\epsilon_{i}^{2}}{2 \sigma^{2}}}
$$

where $\mu_{i}$ denotes the expected value of $y_{i}$ and $\sigma^{2}$ represents its variance. Thus the likelihood for the whole sample is:

$$
\mathcal{L}=\prod_{i=1}^{N} \frac{1}{\sqrt{2 \pi \sigma^{2}}} e^{-\frac{\epsilon_{i}^{2}}{2 \sigma^{2}}}
$$

with $N$ representing the number of forecasts. We derive the corresponding Log-Likelihood function:

$$
\ln \mathcal{L}=N \ln \left(\frac{1}{\sqrt{2 \pi \sigma^{2}}}\right)-\frac{1}{2 \sigma^{2}}\left(\epsilon^{\prime} \epsilon\right)
$$

and simplify further:

$$
\ln \mathcal{L}=\frac{-N}{2} \ln (2 \pi)-\frac{N}{2} \ln \left(\sigma^{2}\right)-\frac{1}{2 \sigma^{2}}\left(\epsilon^{\prime} \epsilon\right)
$$

In a second step we derive the Hessian, which is a matrix of second derivatives of equation (24) with regard to vector $\kappa$ as defined in equation (26). Since the derivates with regard to $\eta_{A}$ and $\eta_{L}$ are identical, both will be referred to as $\eta$ :

$$
H=\frac{\partial^{2} \ln \mathcal{L}}{\partial \kappa \partial \kappa^{\prime}}=\left[\begin{array}{cc}
-\frac{1}{2 \sigma^{2}} \frac{\partial^{2}\left(\epsilon^{\prime} \epsilon\right)}{\partial^{2} \eta} & \frac{1}{2 \sigma^{4}} \frac{\partial\left(\epsilon^{\prime} \epsilon\right)}{\partial \eta} \\
\frac{1}{2 \sigma^{4}} \frac{\partial\left(\epsilon^{\prime} \epsilon\right)}{\partial \eta} & \frac{N}{2 \sigma^{4}}-\frac{\left(\epsilon^{\prime} \epsilon\right)}{\sigma^{6}}
\end{array}\right]
$$

with

$$
\kappa=\left[\begin{array}{c}
\eta \\
\sigma^{2}
\end{array}\right]
$$

It turnes out that $H$ is a diagonal matrix, because the expected value of the first derivative of the sum of squared errors with regard to $\eta$ is null. The covariance matrix of $\kappa$ is the inverse of the negative expected value of the Hessian:

$$
\operatorname{Cov}=[-E[H]]^{-1}
$$

Assuming that $\eta_{A}$ and $\eta_{L}$ follow a truncated multivariate normal distribution and once we have estimated $\eta_{A}$ and $\eta_{L}$ and their covariance matrix as described above, we can draw a large sample of random parameter values for $\eta_{A}$ and $\eta_{L}$ and derive their corresponding income per capita projection as well as their confidence interval until 2100. 


\section{Results}

First, we calibrate the Jones model of economic growth for 26 countries and regions in Europe by minimizing the squared residual between observed and calibrated income from 1850 to 2008. Our parameters of calibration are the production elasticities $\eta_{A}$ and $\eta_{L}$ in the research sector. Table 2 shows all calibrated parameter values for $\eta_{A}$ and $\eta_{L}$ and their corresponding variance and covariance. For most countries and regions we achieve a very good fit. In countries marked with an asterisk, we attain a dissatisfactory fit. In those cases calibrated income remains below observed income between 1850 and 2008 and $\eta_{A}$ and $\eta_{L}$ are underestimated. This is the case, because for these countries our model does not converge for higher values of $\eta_{A}$ and $\eta_{L}$. Given the observed and expected paths of population growth and the assumed path of capital shares between 1850 and 2100, there is no optimal path of consumption which allows for the transition of the model and provides a better fit to observed past income. To differentiate between both we set the barrier at a $5 \%$ deviation of our calibrated income from observed income in 2008. A better fit would be possible to achieve for a different set of parameter values. However, to maintain comparability between countries, we prefer to use the same parameter values for all countries.

The variances in our parameter estimates give us a crude idea of the uncertainty that is tied to future income per capita growth. However, there is no linear relationship between the size of the confidence intervals of future income per capita growth and the variance and covariance of our parameter estimates. Among others this is mostly the case because future population growth is expected to differ tremendously between countries (see United Nations (2010)). To derive the covariance of our point estimates, we need to determine the second derivative of the likelihood function (see equation (25)). However, usually the model does not converge for a deviation of $\eta_{A}$ and $\eta_{L}$ into all directions. In those cases where the corresponding sum of squared errors (SSE) is consequently missing, we construct SSEs by averaging neighboring values. In addition, since the optimum is surrounded by nearly symmetric SSE values, some gaps can be filled by reflecting the data.

In a second step we construct future carbon emission scenarios according to equation (2) using UN population forecasts, own income per capita forecasts and energy as well as emission intensity projections. The resulting future emissions and their components are summarized for Western Europe, Eastern Europe, Europe as a whole and the Former USSR 
Table 2: Coefficients, Variances and Covariances

\begin{tabular}{|c|c|c|c|c|c|}
\hline Country & $\eta_{A}$ & $\operatorname{Var}\left(\eta_{A}\right)$ & $\eta_{L}$ & $\operatorname{Var}\left(\eta_{A}\right)$ & Cov \\
\hline Austria * & 0.55 & 0.0096 & 0.55 & 0.0038 & $1 \mathrm{e}-05>\mathrm{Cov}>-1 \mathrm{e}-05$ \\
\hline Belgium & 0.66 & 0.012 & 0.74 & 0.0041 & -0.0069 \\
\hline Denmark & 0.66 & $7.607 \mathrm{e}-05$ & 0.75 & $1.044 \mathrm{e}-04$ & $1 \mathrm{e}-05>\mathrm{Cov}>-1 \mathrm{e}-05$ \\
\hline Finland & 0.62 & $1.77 \mathrm{e}-04$ & 0.77 & $2.058 \mathrm{e}-04$ & $1 \mathrm{e}-05>\mathrm{Cov}>-1 \mathrm{e}-05$ \\
\hline France * & 0.58 & 0.0027 & 0.81 & 0.0037 & $1 \mathrm{e}-05>\mathrm{Cov}>-1 \mathrm{e}-05$ \\
\hline Germany & 0.63 & $5.149 \mathrm{e}-04$ & 0.78 & $3.56 \mathrm{e}-04$ & $-2.367 \mathrm{e}-04$ \\
\hline Italy & 0.66 & $1.634 \mathrm{e}-04$ & 0.82 & $2.419 \mathrm{e}-04$ & $1 \mathrm{e}-05>\mathrm{Cov}>-1 \mathrm{e}-05$ \\
\hline Netherlands & 0.37 & $1.373 \mathrm{e}-04$ & 0.78 & $154 \mathrm{e}-04$ & $1 \mathrm{e}-05>\mathrm{Cov}>-1 \mathrm{e}-05$ \\
\hline Norway * & 0.60 & $9.997 \mathrm{e}-04$ & 0.74 & 0.0012 & $1 \mathrm{e}-05>\operatorname{Cov}>-1 \mathrm{e}-05$ \\
\hline Sweden * & 0.65 & $5.575 \mathrm{e}-04$ & 0.73 & $7.649 \mathrm{e}-04$ & $-3.323 \mathrm{e}-04$ \\
\hline Switzerland & 0.64 & 0.001 & 0.76 & 0.001 & $1 \mathrm{e}-05>\mathrm{Cov}>-1 \mathrm{e}-05$ \\
\hline UK & 0.59 & $2.202 \mathrm{e}-04$ & 0.64 & $4.025 \mathrm{e}-04$ & $1 \mathrm{e}-05>\mathrm{Cov}>-1 \mathrm{e}-05$ \\
\hline Ireland * & 0.68 & 0.0039 & 0.68 & 0.0301 & $1 \mathrm{e}-05>\mathrm{Cov}>-1 \mathrm{e}-05$ \\
\hline Greece & 0.58 & 0.0023 & 0.75 & 0.0017 & -0.0018 \\
\hline Portugal * & 0.62 & 0.0014 & 0.64 & $6.985 \mathrm{e}-04$ & $1 \mathrm{e}-05>\mathrm{Cov}>-1 \mathrm{e}-05$ \\
\hline Spain * & 0.55 & 0.0122 & 0.55 & 0.0049 & $9.919 \mathrm{e}-04$ \\
\hline Western Europe & 0.71 & $3.919 \mathrm{e}-04$ & 0.73 & $5.561 \mathrm{e}-04$ & $-3.759 \mathrm{e}-04$ \\
\hline Former Czechoslovakia * & 0.60 & 0.0018 & 0.63 & 0.0018 & $1 \mathrm{e}-05>\mathrm{Cov}>-1 \mathrm{e}-05$ \\
\hline Former Yugoslavia * & 0.37 & 0.0017 & 0.78 & 0.0017 & $1 \mathrm{e}-05>\operatorname{Cov}>-1 \mathrm{e}-05$ \\
\hline Bulgaria * & 0.60 & 0.0011 & 0.74 & $8.944 \mathrm{e}-04$ & $1 \mathrm{e}-05>\mathrm{Cov}>-1 \mathrm{e}-05$ \\
\hline Hungary & 0.71 & $8.533 \mathrm{e}-04$ & 0.74 & 0.002 & $-7.795 \mathrm{e}-04$ \\
\hline Poland & 0.43 & $9.436 \mathrm{e}-04$ & 0.77 & 0.0012 & $-6.786 \mathrm{e}-04$ \\
\hline Romania & 0.34 & 0.0011 & 0.82 & 0.0011 & $1 \mathrm{e}-05>\mathrm{Cov}>-1 \mathrm{e}-05$ \\
\hline Eastern Europe & 0.52 & 0.0021 & 0.80 & 0.0013 & $-7.21 \mathrm{e}-04$ \\
\hline Europe & 0.67 & $2.738 \mathrm{e}-04$ & 0.75 & $3.141 \mathrm{e}-04$ & $-1.513 \mathrm{e}-04$ \\
\hline Former USSR & 0.37 & 0.0025 & 0.78 & 0.0027 & $1 \mathrm{e}-05>\mathrm{Cov}>-1 \mathrm{e}-05$ \\
\hline
\end{tabular}

In countries marked with an asterisk calibrated income is more than $5 \%$ lower than observed income in 2008 . 
in figures 4 to 7 . Future economic growth substantially differs between these regions. Table 3 summarizes the mean, upper and lower bound of annual growth rates (averaged over the 21st century). Projected growth is clearly strongest in Western Europe, followed by Eastern Europe and the former USSR. Hence, we find income divergence. In the scenario literature and in Integrated Assessment Modeling this is rather uncommon, yet not unexpected given that other models typically have a Solow growth model. Many analyses assume income convergence between Eastern and Western European countries such that future income per capita growth in Eastern Europe is assumed to be higher than in Western Europe. However, this is not what we have observed in the past. Since 1850 Western European economies have on average been growing at higher rates than Eastern European economies. Therefore, the Jones model will project similar growth patterns into the future. In addition, according to UN forecasts of population growth, the Eastern European population will be strongly reduced after 2000 (see figure 5) while the Western European population size will stay relatively constant (see figure 4). In our model this will also have a negative effect on the economies' growth rate (see equation (14)).

The confidence intervals on income are not symmetric. In Western Europe income is more likely to be underestimated, while in Eastern Europe it is more likely to be overestimated. In addition, the confidence intervals do not have the same width. The variation around the mean in Eastern Europe is much larger than in Western Europe, reflecting greater economic (and other) turmoil in the past.

Table 3: Forecasted annual average growth rates in \%

\begin{tabular}{lccc}
\hline Region & Mean & Upper bound & Lower bound \\
\hline \hline Western Europe & 1.81 & 1.83 & 1.58 \\
Eastern Europe & 1.06 & 1.49 & 0.85 \\
Europe & 1.61 & 1.83 & 1.39 \\
Former USSR & 1.05 & 1.31 & 0.71 \\
\hline
\end{tabular}

Since energy and emission intensities are outside of our model, we choose three constant rates of their annual reduction for which we calculate future paths of carbon emissions. These rates are $0.5 \%, 0.75 \%$ and $1 \%$. The reader may decide for himself which rate he thinks is the most plausible one.

In Eastern Europe (figure 5) and the former USSR (figure 7) we observe a very strong 
decline in past carbon emissions from around 1989 to 1998, which is probably linked to the collapse of the communistic system. However, future carbon emission projections in this paper are based on own forecasts regarding income per capita growth, population growth data and on future energy and emission intensity projections. Hence, these big hikes have a very indirect effect on our carbon emission projections. Further we do not take into account trade and carbon leakage. Peters and Hertwich (2008) find that in a number of European countries in 2001 embodied emissions in imports were significantly higher than in exports. Thus we expect that our point estimates underestimate future consumption based carbon emissions.

Alltogether, in order to keep future carbon emissions roughly constant, Western Europe has to decrease its energy and emission intensities by approximately $1 \%$ per year, while in Eastern Europe and the former USSR an annual reduction by $0.5 \%$ would be sufficient. Since Western Europe is predicted to grow faster, it has to engage in heavier emission reduction schemes than Eastern Europe, to keep its future carbon emissions constant. Notably, Western Europe's energy and emission intensities are below the ones in Eastern Europe in 2008, however, its carbon emissions per capita in 2008 are approximately $21 \%$ higher. In addition, emission forecasts in Eastern Europe and former USSR countries reveal larger confidence intervals due to higher uncertainty in income per capita growth. Further, we find that carbon emission projections turn out differently when a region is calibrated as a whole as opposed to calibrations made on the country level, which are aggregated subsequently (see figure 8). We find that the carbon emissions forecast for Europe is higher, when it is calibrated as a whole and that the confidence interval of this aggregate forecast is much larger than that of the sum of country-wise forecasts. One reason why the disaggregate forecast is substantially lower than the aggregate forecast is that in some cases on the country level $\eta_{A}$ and $\eta_{L}$ are underestimated, because of the nonconvergence of the model for higher values of $\eta_{A}$ and $\eta_{L}$, as was discussed above. Therefore, the aggregate point estimate is a more reliable forecast of future carbon emissions in Europe. However, in those countries where we achieve a good fit of observed income, the average confidence interval is smaller than that of the aggregate forecasts. In those cases the usage of country level data adds information to our estimations and thus turns into more precise forecasts. Because of spatial correlation between countries it makes sense that the aggregate point estimate is surrounded by a larger confidence interval. 


\section{Western Europe}
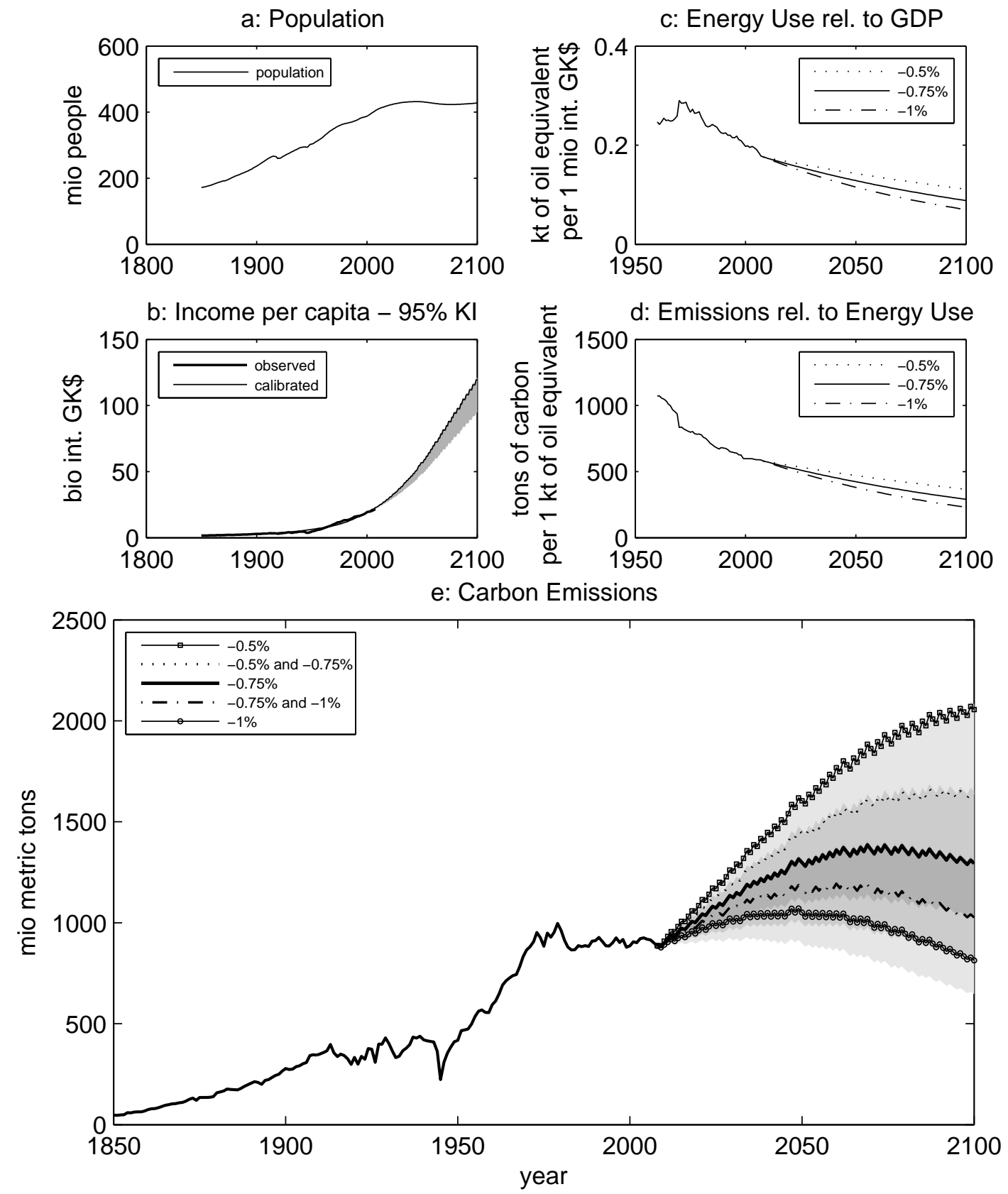

Figure 4: Kaya Decomposition of Carbon Emissions in Western Europe b: Income per Capita after 2008 is sourrounded by a shaded area representing the $95 \%$ confidence interval. c, d: Energy Use rel. to GDP and Emissions rel. to Energy Use after 2008 were extrapolated assuming annual reductions of $0.5 \%, 0.75 \%$ (solid line) and $1 \%$. e: Carbon Emissions after 2008 were calculated for the following annual energy and emission intensity reductions: $0.5 \%$, one $0.5 \%$ and the other $0.75 \%, 0.75 \%$ (solid line), one $0.75 \%$ and the other $1 \%$ and finally $1 \%$ (top to bottom). The shaded areas represent the $95 \%$ confidence intervals of the resprective annual energy and emission intensity reduction with regard to the uncertainty in income per capita. Thus, the darkest area represents the $95 \%$ confidence interval for an annual reduction of the emissions and energy intensity by $0.75 \%$. 


\section{Eastern Europe}
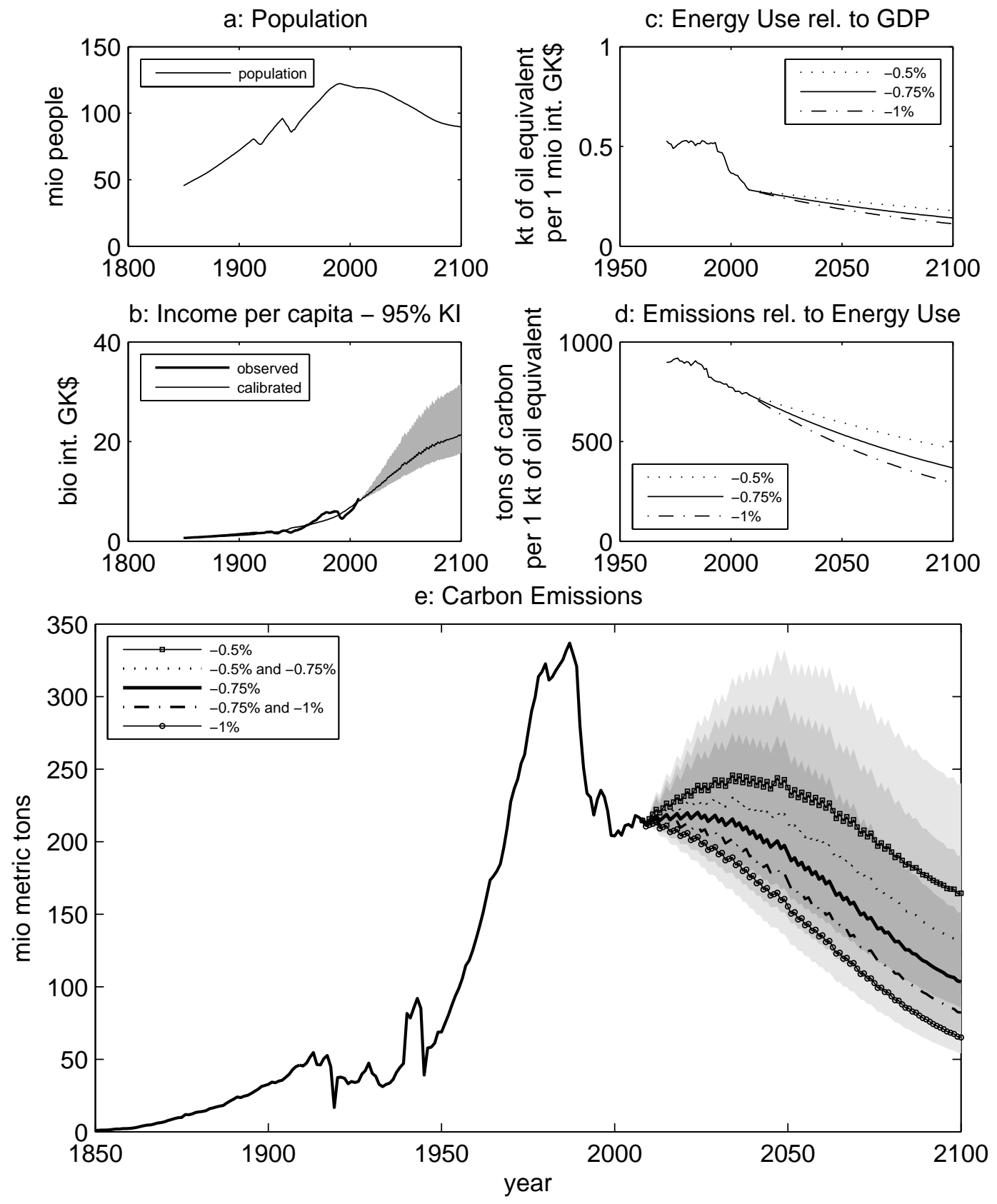

Figure 5: Kaya Decomposition of Carbon Emissions in Eastern Europe See figure 4 for explanations. 


\section{Europe}

a: Population

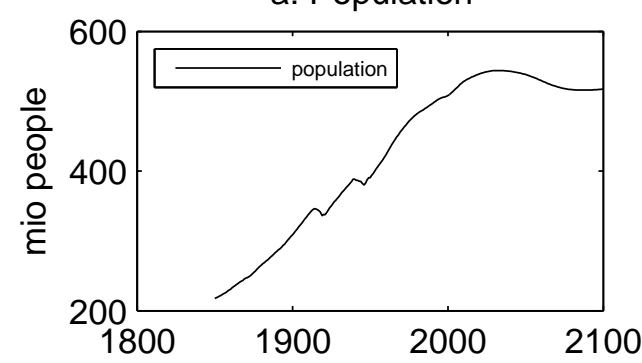

c: Energy Use rel. to GDP

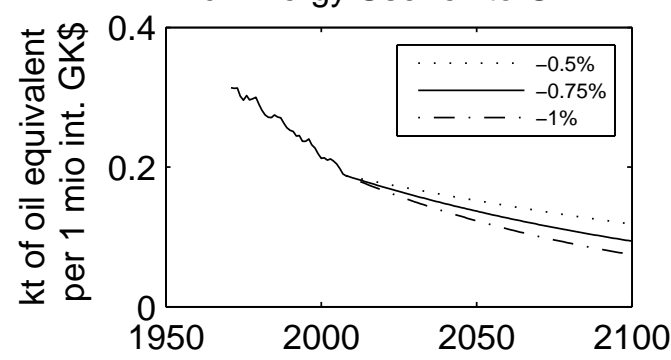

b: Income per capita - 95\% KI
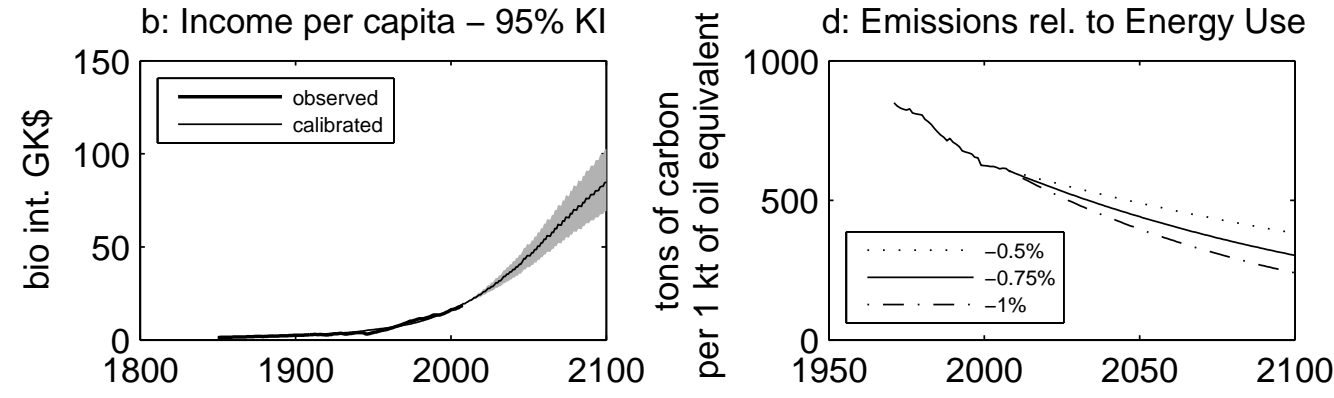

e: Carbon Emissions

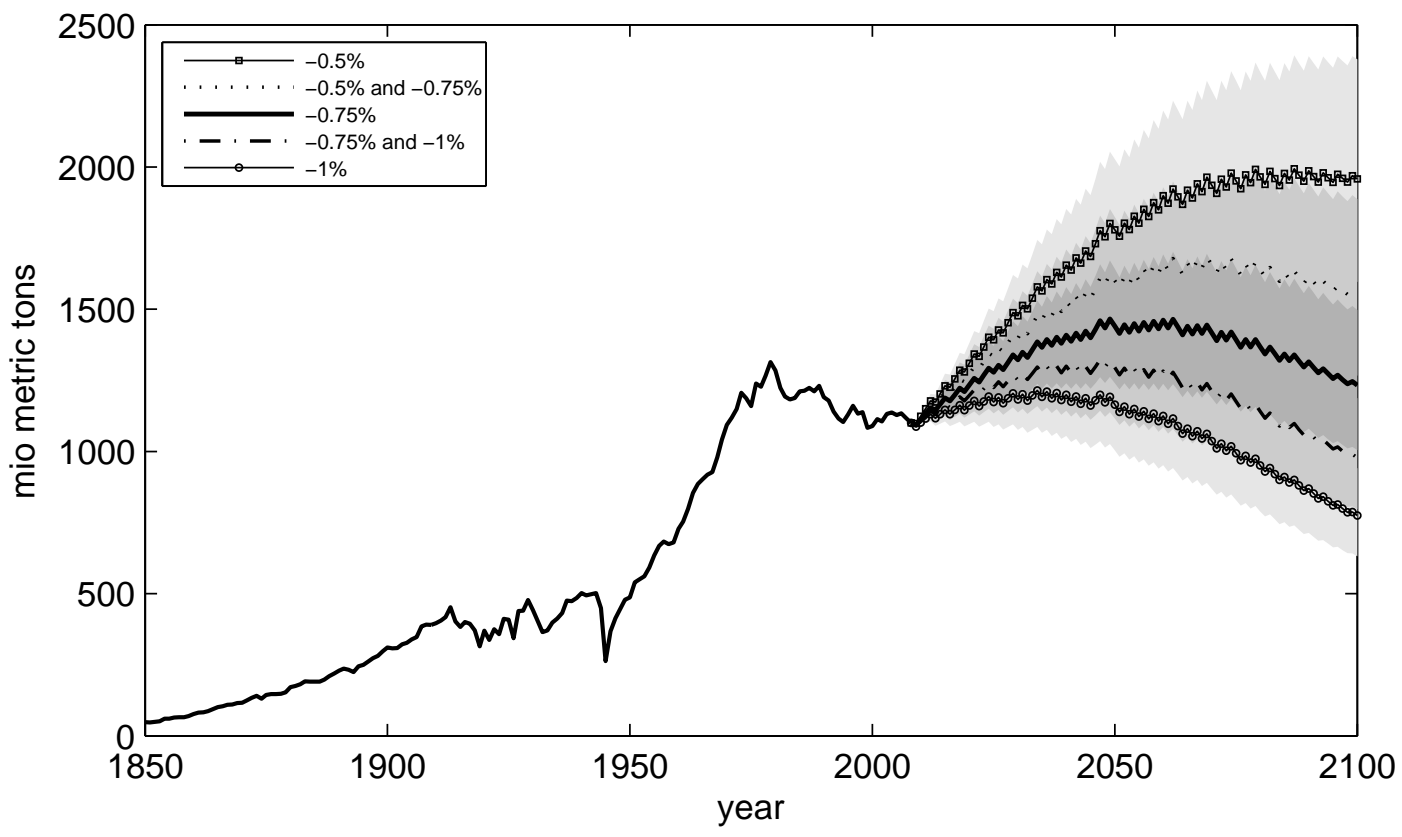

Figure 6: Kaya Decomposition of Carbon Emissions in Europe See figure 4 for explanations. 


\section{Former USSR}
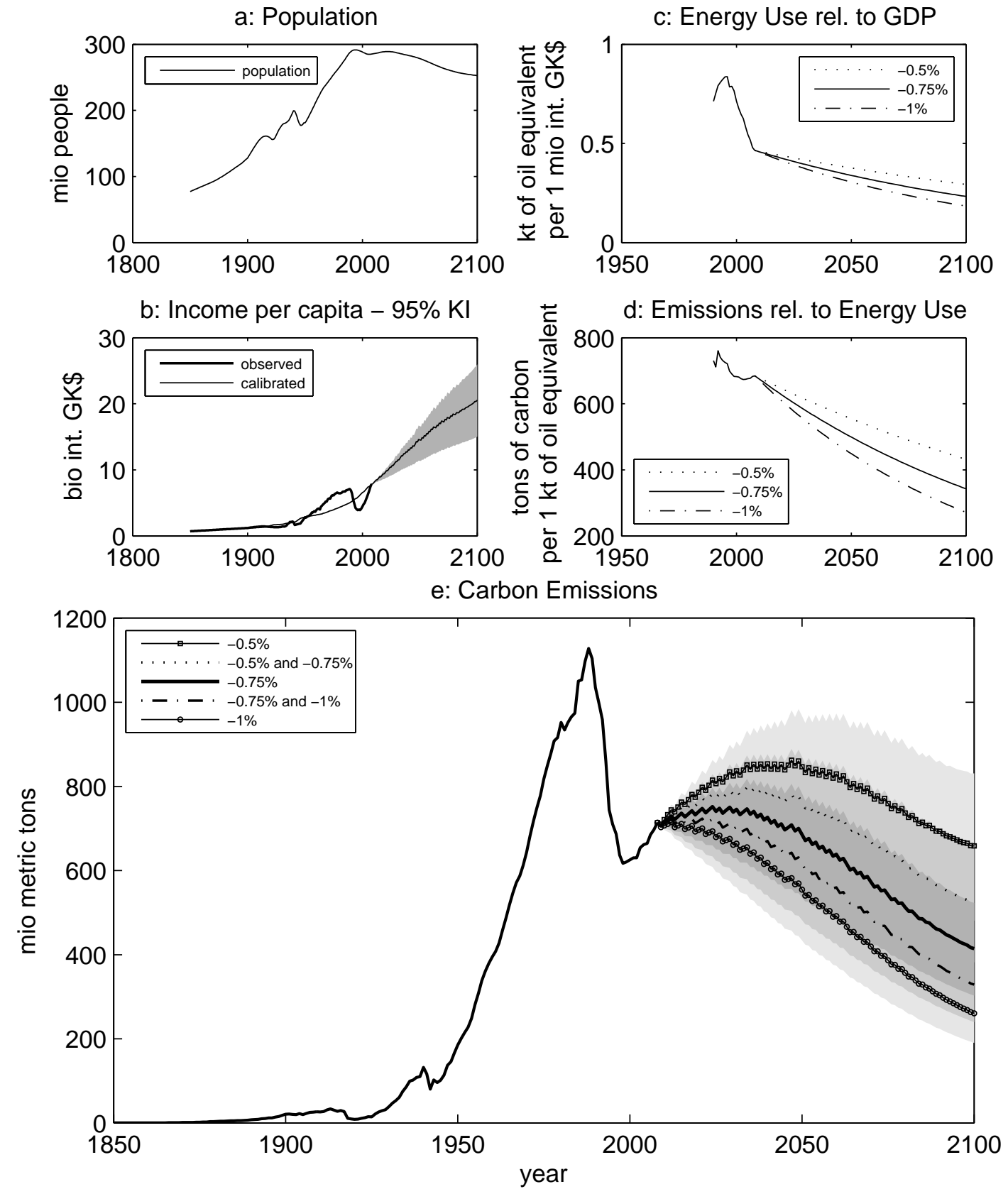

Figure 7: Kaya Decomposition of Carbon Emissions in the former USSR See figure 4 for explanations. 


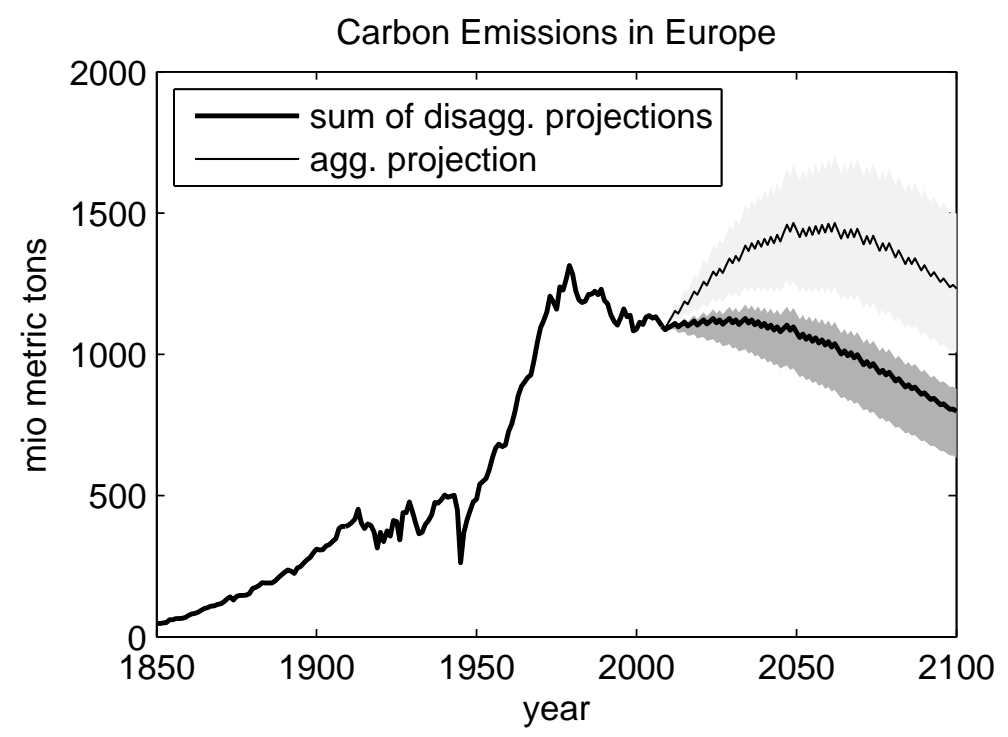

Figure 8: Aggregated and Disaggregated Carbon Emissions Projection for Europe Carbon emissions projections and confidence intervals in Europe if both the energy and the emission intensity are reduced by $0.75 \%$ annually. Aggregate: Europe calibrated as a whole. Disaggregate: The sum of all emissions calibrated on the country level.

\section{A comparison with the SSP framework}

Together with the Fifth Assessment Report of the Intergovernmental Panel on Climate Change (IPCC AR5) a new framework of so-called Shared Socioeconomic Pathways (SSPs) and Representative Concentration Pathways (RCPs) was adopted. In this section we compare our own income projections in this paper with the SSP pathways.

The SSPs comprise of worldwide GDP, population and urbanization data until 2100 grouped into 32 regions. All three time series are available for 5 different scenarios, of which SSP2 is the 'Middle of the Road' scenario, with which we compare our results. Three modelling teams, one each at IIASA, OECD and PIK, have made projections for GDP. Each team used models with different growth dynamics, although they are comparable in the sense that in all three models growth is driven by increases in primary inputs, labor-augmenting efficiency improvements and total factor productivity improvements (Lutz et al. (2014)). However, the degree to which these forces influence economic growth differs in each model. The IIASA model places more emphasis on growth induced by human capital increases, while the PIK model places more weight on the long run total factor productivity growth rate. The OECD model after 2016 is similar to that of PIK. Before this date the data is calibrated towards projections made by OECD, IMF and World Bank. In the SSP2 sce- 
nario all three groups implemented medium total factor productivity growth at the frontier and a medium speed of income convergence between countries. In figures 9 through 11 we compare the three GDP pathways with our own icome projections for Western Europe, Eastern Europe and the Former USSR ${ }^{3}$.

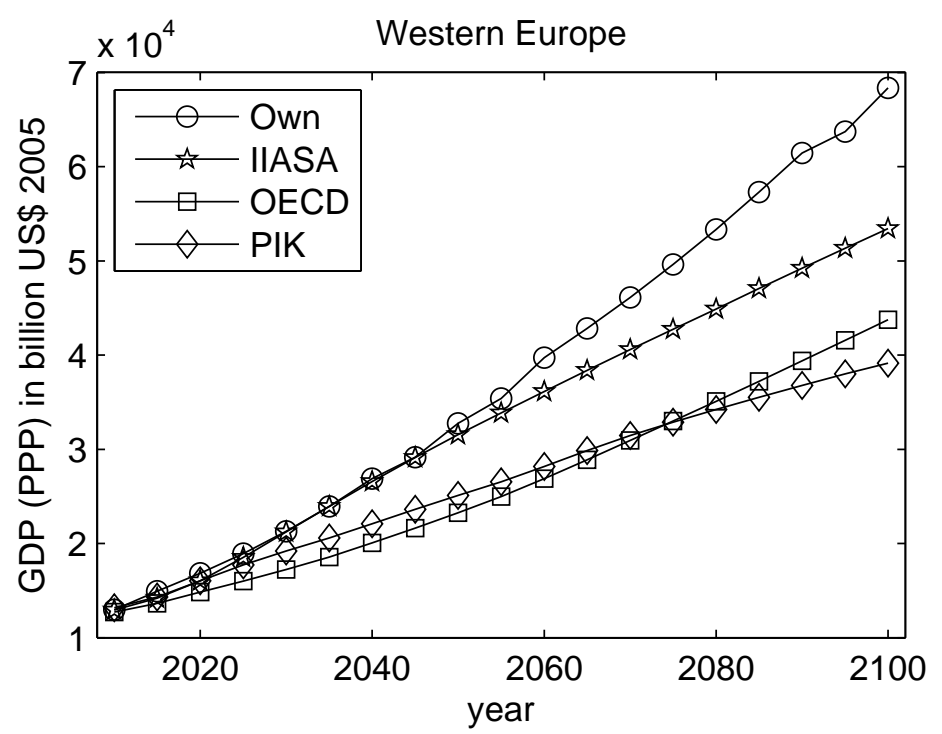

Figure 9: A comparison of the SSP2 pathways ('middle of the road scenario') in Western Europe by IIASA, OECD and PIK with our own results from this paper. (Source: SSP database version 0.9.3 and own calculations)

For Western Europe the income projection of this paper lies above all three GDP pathways projected by IIASA, OECD and PIK. In Eastern Europe and the Former USSR on the contrary our own projection lies below the other three pathways. Since we calibrate the growth dynamics of the Jones model to data since 1850, we pick up stronger growth rates in Western Europe than in the other two regions. Our parameters of calibration, $\eta_{A}$ and $\eta_{L}$, are correspondingly higher in Western Europe than in Eastern Europe and the Former USSR. All other parameter choices being the same, the only other influence on the growth dynamics is population growth. Since according to the United Nations (see United Nations (2010)) future population growth in Western Europe will be higher than in Eastern Europe and the Former USSR, income growth is faster, too. If we had used the

\footnotetext{
${ }^{3}$ The SSP data on GDP is corrected for purchasing power parities and given in 2005 US \$. Since our own projections are made in 1995 GK \$, we normalize our own time series such that income in 2010 is the same as in the SSP data. Regional specifications do not completely match. See appendix B for a comparison.
} 


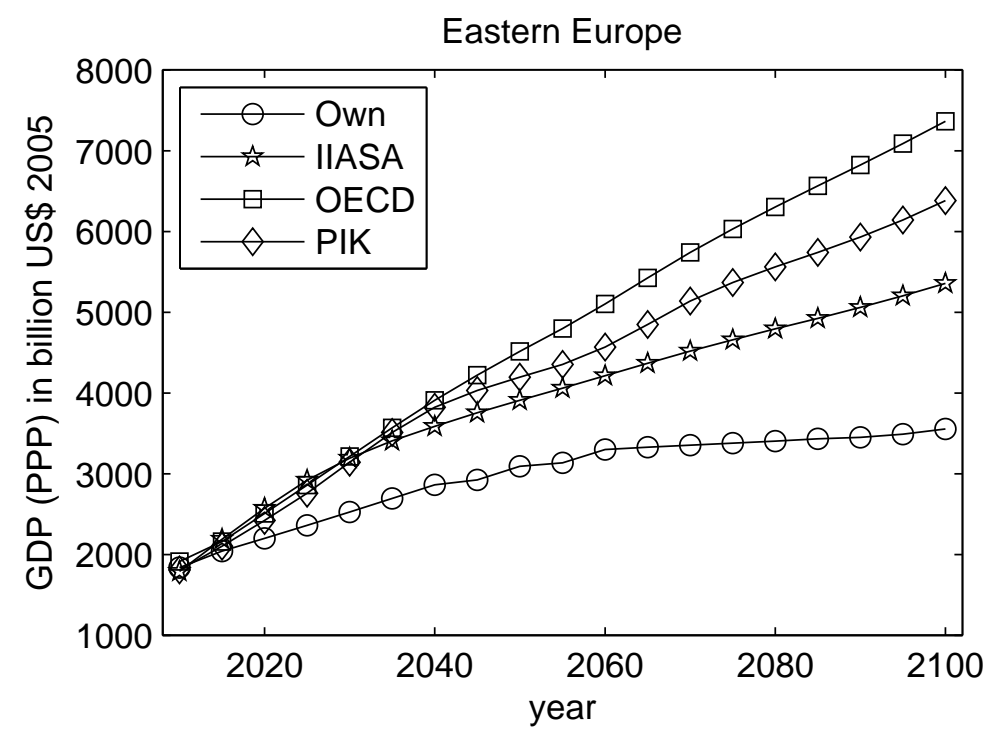

Figure 10: A comparison of the SSP2 pathways ('middle of the road scenario') in Eastern Europe by IIASA, OECD and PIK with our own results from this paper. (Source: SSP database version 0.9.3 and own calculations)

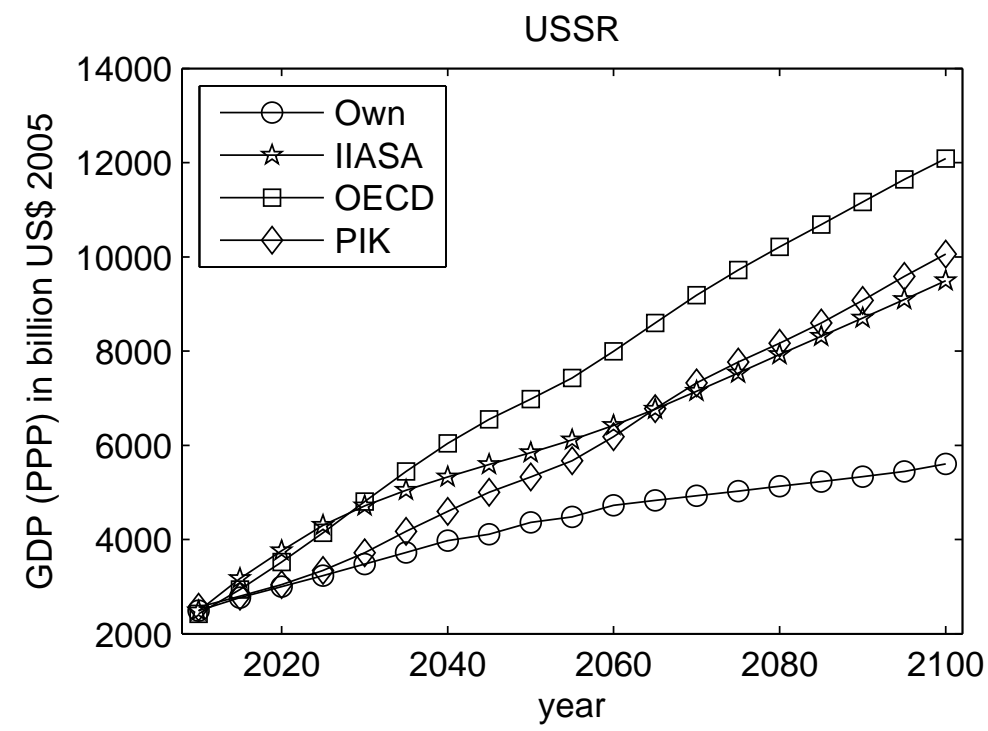

Figure 11: A comparison of the SSP2 pathways ('middle of the road scenario') in the former USSR by IIASA, OECD and PIK with our own results from this paper. (Source: SSP database version 0.9.3 and own calculations) 
population pathway included in the SSP2 scenario, growth in Western Europe according to the Jones model would be even stronger, since the SSP2 population forecasts are more optimistic than the United Nations data base.

Altogether we achieve a stronger income divergence than is projected in the SSP2 pathways.

There are four RCP pathways of carbon dioxide emissions, each developed by a different group of modellers. The four models which were employed are IMAGE (van Vuuren et al. (2007)), MiniCAM (Smith and Wigley (2006) and Wise et al. (2009)), AIM (Fujino et al. (2006) and Hijioka et al. (2008)) and MESSAGE (Riahi, Gruebler and Nakicenovic (2007)). The RCP scenarios aim at providing a consistent set of pathways of the components of radiative forcing. A summary of theese pathways is available in van Vuuren et al. (2011). However, a comparison between our own emission forecasts in this paper and the RCP pathways is not expedient, since our focus lies on the economic model, which drives future income growth and hence carbon emissions and the RCP pathways do not have an economic model at their core.

\section{Sensitivity Analysis}

So far we have discussed carbon emission projections in Europe and former USSR countries depending on a certain set of parameter choices. In this section we will evaluate the sensitivity of our results towards the discount rate, $\rho$, and towards the capital share, $(1-\sigma)$. In the past there has been an intense debate about different parameterizations of discount rates. The lower the discount rate is, the stronger is the utility of today's households influenced by future generations welfare. Consequently, the debate about discount rates is strongly influenced by different moral views. In this study we refrain from a discussion of this sort, but we do want to provide insights into the sensitivity of our results towards the discount rate. A high discount rate leads to more consumption and lower savings today and thus to a lower level of future income per capita along the entire growth path. Correspondingly in figure 12 we observe that a higher discount rate leads to lower income per capita in 2100 . This will also imply lower emissions in the future. In accordance to the Keynes-Ramsey rule this is also true for economic growth on the balanced growth path. However, due to transitory dynamics the balanced growth path is not achieved before 2100 . In addition, our fit seems to improve with higher discount rates (see figure 14). Overall 
the sensitivity towards the discount rate is rather low. For a variation of discount rates between $1 \%$ to $3 \% \eta_{A}$ and $\eta_{L}$ stay entirely constant, income per capita decreases by $4.7 \%$ and the root mean squared error (RMSE) by $1.8 \%$.

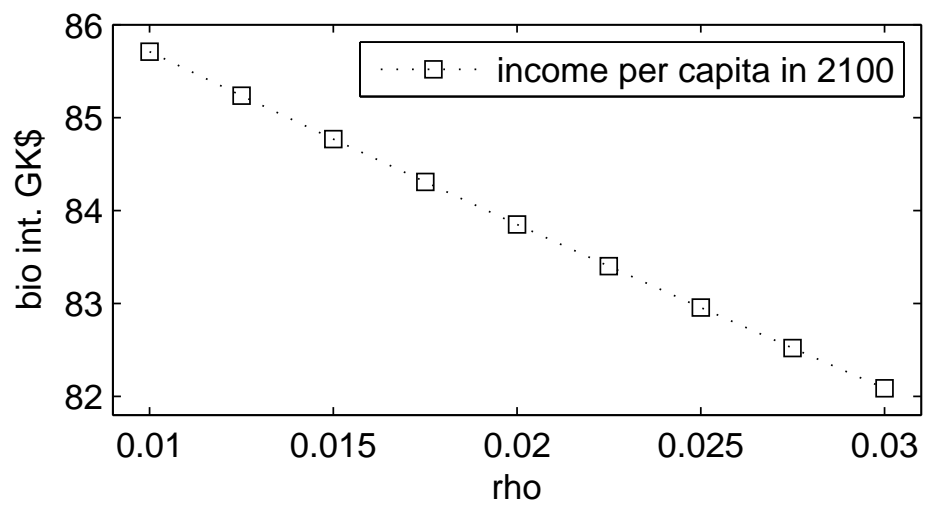

Figure 12: Sensitivity analysis towards the discount rate - Europe

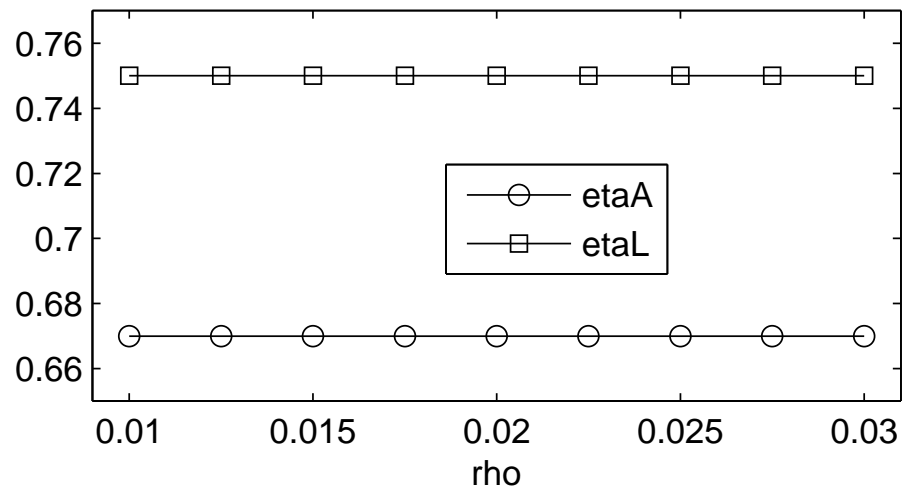

Figure 13: Sensitivity analysis towards the discount rate - Europe

We have already discussed our reasons for choosing an increasing capital share over time in section 2. In the modelling literature (see for instance the DICE 2013 model) it is commonplace to assume a constant capital share. In addition, sensitivity analyses towards the capital share are rare. In this section we increase the capital share from 0.25 in 1850 to 0.3 up to 0.5 in 2100 and we find that this choice has tremendous impacts on income per capita growth. Income per capita in 2100 increases by roughly $60 \%$ if the capital share amounts to 0.5 in 2100 compared to 0.3 (see figure 15). Taking into account that population growth rates in Europe will continue to decline, it is intuitively clear that increasing capital shares have a strong and positive impact on growth. So far this has been neglected in the literature. The fit of our model improves with a lower capital share in 2100. According to 


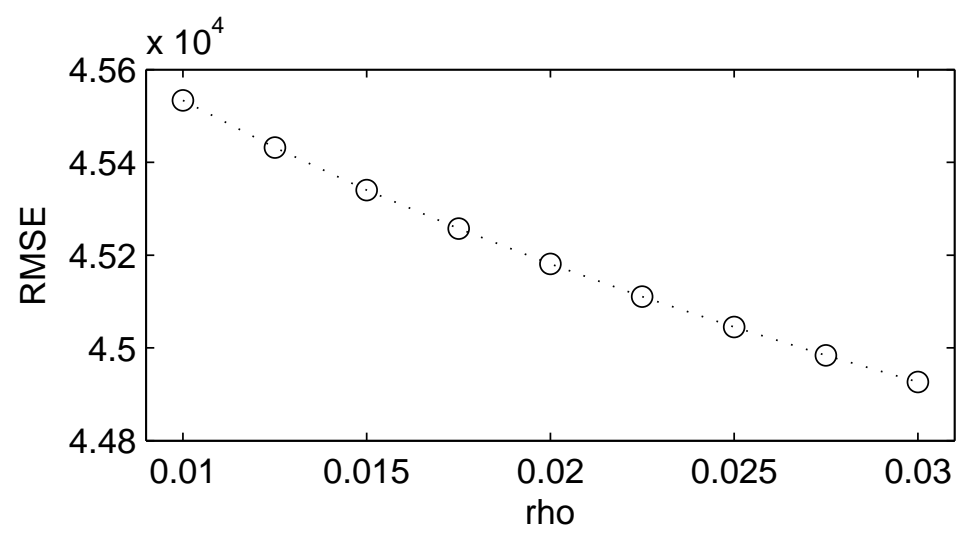

Figure 14: Sensitivity analysis towards the discount rate - Europe

figure 17 capital shares of more than 0.45 in 2100 yield an unproportionally large error.

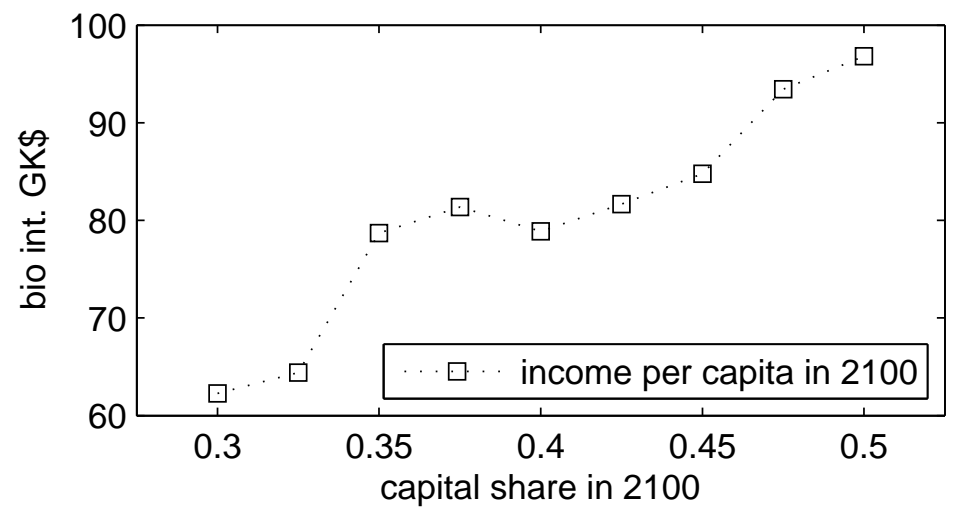

Figure 15: Sensitivity analysis towards the capital share - Europe

\section{Conclusions}

In this paper we endogenize economic growth in the construction of carbon dioxide emission scenarios. Our results indicate the importance of endogenous growth modeling in the scenario literature and potentially for Integrated Assessment Modeling. We show that endogenizing economic growth leads to different income projections than what is commonly assumed for the construction of carbon emission scenarios. In particular, we find stronger annual average growth rates in countries with a higher current income per capita. As a consequence these countries have to lower their annual energy and emission intensities by more to keep their total carbon emissions constant. While Western Europe would have to decrease its energy and emission intensities by approximately $1 \%$ per year, in Eastern 


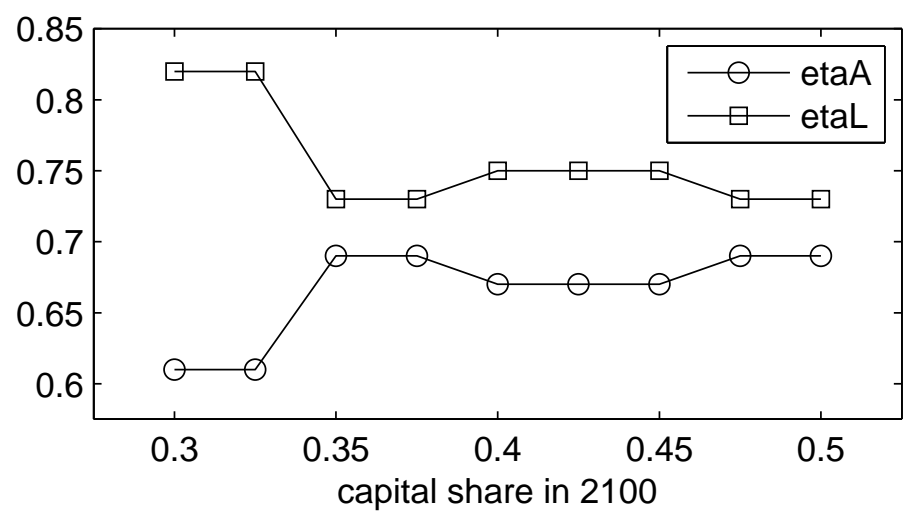

Figure 16: Sensitivity analysis towards the capital share - Europe

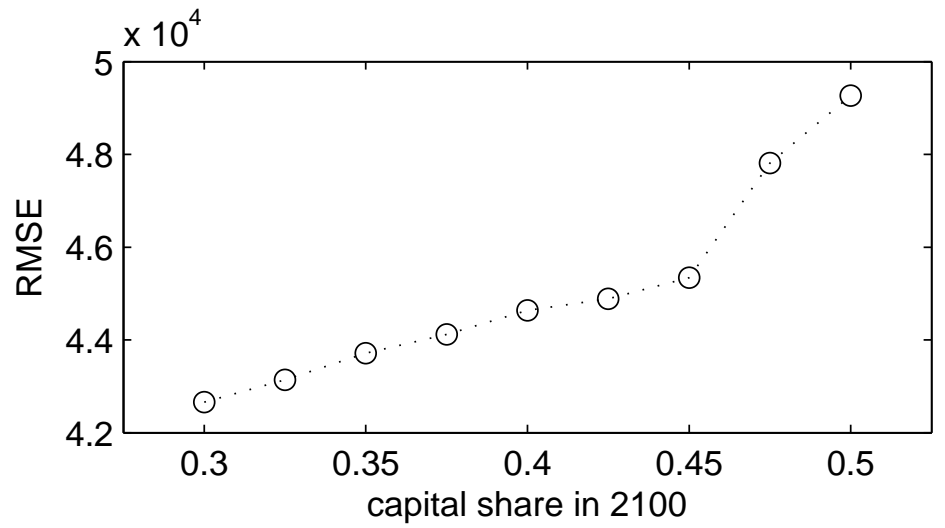

Figure 17: Sensitivity analysis towards the capital share - Europe 
Europe and the former USSR $0.5 \%$ per year seem to suffice. If we regard both regions independently from each other, the same goal of keeping carbon emissions constant would lead to more radical policy measures to be taken in Western Europe than in Eastern Europe. Taking into account past reductions in the energy intensity in Western Europe (see figure 4) a continued yearly reduction by $1 \%$ seems achievable. A yearly reduction of the emissions intensity by $1 \%$ however, entails a reduction of the same by more than $50 \%$ by 2100. In other words, in order to keep future carbon emissions in Western Europe relatively constant, it would have to substitute $50 \%$ of its fossil energy supplies by non-fossil sources. This may not be feasible without severe political intervention.

Further we find that conducting forecasts on the country level adds to the overall precision of our projections. In particular, when income per capita in Europe is calibrated as a whole, there is more uncertainty tied to corresponding projections of future carbon dioxide emissions than there is to the sum of country-wise forecasts. The sensitivity analysis reveals that our income and carbon emission projections are rather robust to the discount rate, while they are strongly dependent on the capital share. Although there has been an intense debate about the former, in the scenario literature capital shares are typically assumed to stay at a constant and seemingly arbitrary level. We propose that future work could shed some more light on the implications of certain assumptions concerning the capital share.

This model does not entail components for the carbon cycle, climate, and impacts of climate change. In the theoretical literature endogenous growth models including damage functions have already been proposed (see section 1). In the future a simultaneous calibration of both together with endogenized energy and emission intensities would be desirable (at this point we are not referring to endogenous technological change - this has been done). Pindyck (2013) and Stern (2013) underline the importance of a better understanding of damage functions and related assumptions regarding their nature. Likewise it does matter in endogenous growth modeling whether we assume damages to affect stocks or levels. 


\section{A. Transformation of the Jones model into stationary variables}

All state and control variables are transformed into stationary values using:

$$
\hat{A}=\frac{A}{L^{\beta_{A}}}, \hat{K}=\frac{K}{L^{\beta_{K}}}, \hat{C}=\frac{C}{L^{\beta_{K}}} \text { and } \hat{P}_{A}=\frac{P_{A}}{L} \text { with } \beta_{A}=\frac{\eta_{L}}{1-\eta_{A}} \quad \text { and } \beta_{K}=\frac{1-\eta_{A}+\eta_{L}}{1-\eta_{A}} .
$$

Thus we solve equations (28) through (32) numerically.

$$
\begin{gathered}
\dot{\hat{A}}=\alpha_{J} \hat{A}^{\eta_{A}}(1-\phi)^{\eta_{L}}-\hat{A} \beta_{A} n \\
\dot{\hat{K}}=(\hat{A} \phi)^{\sigma} \hat{K}^{1-\sigma}-\hat{C}-\left(\delta+\beta_{K} n\right) \hat{K} \\
\dot{\hat{C}}=\frac{\hat{C}}{\theta}\left((1-\sigma)^{2}(\hat{A} \phi)^{\sigma} \hat{K}^{-\sigma}-\rho-\delta-n+\theta n\right)-n \beta_{K} \hat{C} \\
\dot{\hat{P}}=\left((1-\sigma)^{2}(\hat{A} \phi)^{\sigma} \hat{K}^{-\sigma}-n\right) \hat{P}_{A}-\sigma(1-\sigma) \hat{A}^{\sigma-1} \phi^{\sigma} \hat{K}^{1-\sigma} \\
\sigma \hat{A}^{\sigma} \phi^{\sigma-1} \hat{K}^{1-\sigma}=\hat{P}_{A} \alpha_{J} \hat{A}^{\eta_{A}}(1-\phi)^{\eta_{L}-1}
\end{gathered}
$$

\section{B. Region definitions}


Table 4: Region definitions in this paper an in the SSP database

\begin{tabular}{|c|c|c|}
\hline Region & This paper & SSP database \\
\hline Western Europe & $\begin{array}{l}\text { Austria, Belgium, Denmark, } \\
\text { Finland, France, Germany, } \\
\text { Italy, Netherlands, Norway, } \\
\text { Sweden, Switzerland, UK, } \\
\text { Ireland, Greece, Portugal, } \\
\text { Spain }\end{array}$ & $\begin{array}{l}\text { Austria, Belgium, Denmark, } \\
\text { Finland, France, Germany, } \\
\text { Greece, Ireland, Italy, } \\
\text { Luxembourg, Netherlands, } \\
\text { Portugal, Spain, Sweden, } \\
\text { UK, Iceland, Norway, } \\
\text { Switzerland }\end{array}$ \\
\hline Eastern Europe & $\begin{array}{l}\text { Bulgaria, Hungary, Poland, } \\
\text { Romania, Former } \\
\text { Czechoslovakia (Czech- } \\
\text { Republik, Slovakia), } \\
\text { Former Yugoslavia ( } \\
\text { Yugoslavia, Bosnia, Croatia, } \\
\text { Macedonia, Slovenia, Serbia/ } \\
\text { Montenegro/ Kosovo) }\end{array}$ & $\begin{array}{l}\text { Albania, Bosnia and } \\
\text { Herzegovina, Croatia, } \\
\text { Montenegro, Serbia, The } \\
\text { Albania, Bosnia and } \\
\text { former Yugoslav Republic } \\
\text { Albania, Bosnia and } \\
\text { Albania, Bosnia and } \\
\text { Albania, Bosnia and } \\
\text { of Macedonia, Cyprus, } \\
\text { Czech Republik, Estonia, } \\
\text { Hungary, Malta, Poland, } \\
\text { Slovakia, Slovenia, Bulgaria, } \\
\text { Latvia, Lithuania, Romania }\end{array}$ \\
\hline Former USSR & $\begin{array}{l}\text { Former USSR (Armenia, } \\
\text { Azerbaijan, Belarus, } \\
\text { Estonia, Georgia, } \\
\text { Kazakhstan, Kyrgyzstan, } \\
\text { Latvia, Lithuania, Moldova, } \\
\text { Russia, Tajikistan, } \\
\text { Turkmenistan, Ukraine, } \\
\text { Uzbekistan) }\end{array}$ & $\begin{array}{l}\text { Russian Federation, Belarus, } \\
\text { Republic of Moldova, Ukraine }\end{array}$ \\
\hline
\end{tabular}




\section{References}

Acemoglu, D. et al. (2012): The environment and directed technical change. American Economic Review, 102, 131-166

Acemoglu, Daron (2009): Introduction to Modern Economic Growth. Princeton University Press

Amemiya, Takeshi (1985): Advanced Econometrics. Harvard University Press

Blanchard, Olivier J. (1997): The Medium Run. Brookings Papers on Economic Activity, 1997 No. 2, 89-158

Boden, T. A., Andres, R. J. and Marland, G. (2013): Global, Regional and National Fossil-Fuel $\mathrm{CO}_{2}$ Emissions. Carbon Dioxide Information Analysis Center, Oak Ridge National Laboratory, U.S. Department of Energy, Oak Ridge, Tenn., U.S.A 〈URL: http://cdiac.ornl.gov/trends/emis/tre_coun.html

Bosetti, Valentina, Massetti, Emanuele and Tavoni, Massimo (2007): The WITCH Model. Structure, Baseline, Solutions. Fondazione Eni Enrico Mattei (10.2007). - Nota di Lavoro

Bovenberg, A. Lans and Smulders, Sjak (1995): Environmental quality and pollution-augmenting technological change in a two-sector endogenous growth model. Journal of Public Economics, 57, 369-391

Bretschger, Lucas, Ramer, Roger and Schwark, Florentine (2011): Growth effects of carbon policies: Applying a fully dynamic CGE model with heterogeneous capital. Resource and Energy Economics, 33, 963-980

Eicher, Theo S. and Turnovsky, Stephen J. (1999): Convergence in a Two-Sector Nonscale Growth Model. Journal of Economic Growth, 4 No. 4, 413-428 〈URL: http://faculty.washington.edu/te/papers/conver ${ }^{\sim}$.pdf $\rangle$

Foellmi, Reto and Zweimüller, Josef (2008): Structural change, Engel's consumption cycles and Kaldor's facts of economic growth. Journal of Monetary Economics, 55, $1317-1328$

Fujino, J. et al. (2006): Multi-gas mitigation analysis on stabilization scenarios using AIM global model. The Energy Journal Special Issue 
Gerlagh, Reyer and Zwaan, Bob van der (2003): Gross world product and consumption in a global warming model with endogenous technological change. Resource and Energy Economics, 25, 35-57 /URL: http://www.cbe.csueastbay . edu/ alima/courses/4306/Articles/GerlaghVanDerZwaan.pdf $\rangle$

Gerlagh, Reyer et al. (2004): Impacts of $\mathrm{CO}_{2}$ - Taxes in an Economy with Niche Markets and Learning-by-Doing. Environmental and Resource Economics, 28, 367394

Hijioka, Y. et al. (2008): Global GHG emissions scenarios under GHG concentration stabilization targets. Journal of Global Environmental Engineering, 13, 97-108

Hoffert, Martin I. et al. (1998): Energy implications of future stabilization of atmospheric CO2 content. Nature, 395, 881-884 〈URL: http://stephenschneider. stanford.edu/Publications/PDF_Papers/HoffertEtAl.pdf $\rangle$

Jones, Charles I. (1995): R\&D-Based Models of Economic Growth. Journal of Political Economy, 103 No. 4, 759-784 〈URL: http://www.jstor.org/stable/2138581〉

Jones, Charles I. (2003): Growth, capital shares, and a new perspective on production functions. - Working Paper

Kaldor, Nicholas (1961): Capital Accumulation and Economic Growth. In Lutz, F. and Hague, D.C., editors: The Theory of capital. New York: St. Martin's Press, $177-222$

Kongsamut, Piyabha, Rebelo, Sergio and Xie, Danyang (2001): Beyond Balanced Growth. Review of Economic Studies, 68 No. 4, 869-882

Koopmans, Tjalling C. (1965): On the Concept of Optimal Economic Growth. In The Econometric Approach to Development Planning Amsterdam: North-Holland, $225-295$

Lutz, Wolfgang et al. (2014): Supplementary note for the SSP data sets. online 〈URL: https://secure.iiasa.ac.at/web-apps/ene/SspDb/static/download/ ssp_suplementary\%20text.pdf $\rangle$

Maddison, Angus (2010): Historical Statistics. /URL: http://www.ggdc.net/ MADDISON/oriindex.htm〉 
Nakicenovic, Nebojsa et al. (2000): Special Report on Emissions Scenarios : a special report of Working Group III of the Intergovernmental Panel on Climate Change. 〈URL: http://www.osti.gov/scitech/servlets/purl/15009867〉

Peters, Glen P. and Hertwich, Edgar G. (2008): $\mathrm{CO}_{2}$ Embodied in International Trade with Implications for Global Climate Policy. Environmental Science and Technology, 42 No. 5, 1401-1407

Pindyck, Robert S. (2013): Climate Change Policy: What Do the Models Tell Us? Journal of Economic Literature, 51 No. 3, 860-872

Popp, David (2004): ENTICE: endogenous technological change in the DICE model of global warming. Journal of Environmental Economics and Management, 48 No. 1, $742-768$

Pottier, Antonin, Hourcade, Jean-Charles and Espagne, Etienne (2014): Modelling the redirection of technical change: The pitfalls of incorporeal visions of the economy. Energy Economics, 42, 213-218

Riahi, K., Gruebler, A. and Nakicenovic, N. (2007): Scenarios of long-term socioeconomic and environmental development un der climate stabilization. Technological Forecasting and Social Change, 74, 887-935

Romer, Paul M. (1990): Endogenous Technological Change. Journal of Political Economy, 98 No. 5, 71-102 〈URL: http://www.jstor.org/stable/2937632〉

Smith, S.J. and Wigley, T.M.L. (2006): Multi-Gas Forcing Stabilization with the MiniCAM. Energy Journal, Special Issue 3, 373-391

Smulders, Sjak (1995): Entropy, Environment, and Endogenous Economic Growth. International Tax and Public Finance, 2, 319-340

Solow, Robert M. (1956): A Contribution to the Theory of Economic Growth. Quarterly Journal of Economics, 70, 65-94

Stern, Nicholas (2013): The Structure of Economic ModModel of the Potential Impacts of Climate Change: Grafting Gross Underestimation of Risk onto Already Narrow Science Models. Journal of Economic Literature, 2013 In Pindyck (2013): Journal of Economic Literature 
Tol, Richard S. J. and Pacala, Stephen W. (2009): Understanding Long-Term Energy Use and Carbon Dioxide Emissions in the USA. Journal of Policy Modeling, 31 No. $3,425-445$

Trimborn, Timo (2008): Multidimensional transitional dynamics: a simple numerical procedure. Macroeconomic Dynamics, 12 No. 03, 301-319 /URL: http://www. econstor.eu/dspace/bitstream/10419/25790/1/517004364.PDF $\rangle$

United Nations (2010): World Population Prospects: The 2010 Revision. 〈URL: http: //esa.un.org/unpd/wpp/Excel-Data/population.htm〉

van Vuuren, Detlef P. et al. (2011): A special issue on the RCPs. Climatic Change, 109, 1-4 〈URL: http://dx.doi.org/10.1007/s10584-011-0157-y〉

van Vuuren, Detlef P. et al. (2007): Stabilizing greenhouse gas concentrations at low levels: an assessment of reduction strategies and costs. Climatic Change, 81, 119-159

Wise, M.A. et al. (2009): Implications of Limiting CO2 Concentrations for Land Use and Energy. Science, 324, 1183-1186 